\title{
Free Radical Activity as Diagnostic and Prognostic Criteria in Solid Tumors and Their Therapy
}

\author{
E. I. Erlykina, L. M. Obukhova*, T. V. Kopytova \\ Federal State Budgetary Educational Institution of Higher Education «Privolzhsky Research Medical University» of the Ministry of \\ Health of the Russian Federation, Nizhny Novgorod, Russia \\ Email: biochem@ pimunn.ru, ${ }^{*}$ Obuhova LM@yandex.ru
}

How to cite this paper: Erlykina, E.I., Obukhova, L.M. and Kopytova, T.V. (2018) Free Radical Activity as Diagnostic and Prognostic Criteria in Solid Tumors and Their Therapy. Journal of Biosciences and Medicines, 6, 1-12.

https://doi.org/10.4236/jbm.2018.612001

Received: October 24, 2018

Accepted: November 27, 2018

Published: November 30, 2018

Copyright ( $) 2018$ by authors and Scientific Research Publishing Inc. This work is licensed under the Creative Commons Attribution International License (CC BY 4.0).

http://creativecommons.org/licenses/by/4.0/

\begin{abstract}
Blood plasma of 39 cancer patients who had not previously undergone anti-tumor treatment, and 21 patients with recurrent epithelial tissues cancer before treatment and after the first course of chemotherapy were investigated. The treatment effectiveness of patients with relapse was evaluated throughout the year. The control group was the blood plasma of 14 healthy people. Free radical activity and oxidative modification of proteins were assessed in blood plasma. In malignant neoplasms of epithelial tissues, free radical activity and oxidative modification of plasma proteins are significantly higher. At the initial stages of carcinogenesis, the oxidative modification level of plasma proteins increases both due to aldehyde and ketone carbonyl derivatives. In the terminal stage of malignant tumors, an increase in the oxidative modification of proteins occurs due to aliphatic ketone dinitrophenyl hydrazones, which are the markers of protein aggregation characteristic of the late stages of oxidative stress. In case of an objective response to polychemotherapy, there is a significant decrease in free radical plasma activity after the first course of therapy and a significant increase in carbonyl derivatives recorded at a wavelength of $230 \mathrm{~nm}$, which can serve as a marker of its effectiveness.
\end{abstract}

\section{Keywords}

Free Radical Activity, Oxidative Modification, Blood Plasma Proteins, Cancer, Chemotherapy Efficiency

\section{Introduction}

A characteristic feature of malignant tumors is the absence of symptoms in the initial period of the disease. The efficiency of treatment of neoplasms increases 
significantly when they are identified at an early stage. If cancer is detected in the early stages about $90 \%$ of patients are cured, about $75 \%$ of patients are cured in the second stage, $75 \%$ at the third stage, and less than $10 \%$ at the fourth stage [1]. One of the major drawbacks of chemotherapy is its empirical nature due to the lack of reliable evidence of the sensitivity of tumors to cytostatic agents. Thus, a relationship between a high content of thymidylate synthase and tumor resistance to 5-fluorouracil was demonstrated [2]. However, this method has a number of special features: a difference of expression of thymidylate synthase in the primary neoplasm and metastases; there may be an increase in its activity during treatment by fluoropyrimidines as well as dependence on a number of clinical factors [3].

Therefore, the actual problems of modern oncology are in identification of patients in the early stages of the disease and in determination of the efficiency of chemotherapy at the initial stage of treatment.

The concentration of reactive oxygen species (ROS) is one of the pathogenetic factors of carcinogenesis [4]. The development of blastomatous process is accompanied by increased levels of superoxide anion-radical and other reactive oxygen species, by development of oxidative stress in the body [5].

The proteins are one of the main substrates, affected by ROS, due to special structure of their molecules [6]. By interacting with blood plasma proteins, free radical oxidation products lead to their modification. During this affect there is a change in the structure of protein molecules, leading to disruption of their physico-chemical, biological and conformational properties [7]. Protein oxidation is a reliable and early marker of oxidative damage [8].

In view of the above, the aim of this study is to analyze the relationship of activity of free radical processes in the blood plasma with the presence and stage of tumor formation and the efficiency of chemotherapy in malignant tumors of epithelial tissues.

\section{Materials and Methods}

\subsection{Patients and Samples}

The object of the study was the blood plasma of 39 patients not previously exposed to anti-tumor treatment: 17 males (47 - 74 years) and 22 females (34 - 67 years) with cancer of kidney, bladder, prostate, ovaries, larynx, colon, uterus, pancreas, and gallbladder. Analysis of distribution of patients in stages and the diagnosis showed that the $\mathrm{I}^{\text {st }}$ stage was with $19 \%$ of patients, the $\mathrm{II}^{\text {nd }}$ stage was with $19 \%$, the III $^{\text {rd }}$ stage with $42 \%$, the IV $^{\text {th }}$ stage was $20 \%$; cancer of: kidney was detected in 8 patients $(27 \%)$, bladder in $3(6 \%)$, prostate in $3(6 \%)$, ovarian in 2 (5\%), larynx in $2(5 \%)$, intestine in $14(37 \%)$, uterus in $3(6 \%)$, pancreas in 1 (4\%), gall bladder in $1(4 \%)$.

The blood plasma of 21 patients was also examined with recurrent cancer of epithelial tissues before treatment and after the first course of chemotherapy. The first group included patients with recurrent colorectal cancer: 5 men and 6 
women aged 57 to 62 years. All these patients had the IV ${ }^{\text {th }}$ stage of disease with distant metastases. The second group consisted of patients with recurrent bladder cancer: 8 men and 2 women aged 48 to 64 years. The patients of this group had the III ${ }^{\text {rd }}$ stage of disease without metastasis.

The control blood plasma was taken from 14 actually healthy people without harmful habits: 6 men (24 - 74 years) and 8 women (25 - 65 years).

\subsection{Treatment and Observation}

Treatment of recurrent colon cancer included 8 courses of chemotherapy by cytostatics in conventional doses according to Protocol of International Clinical Recommendations. In case of relapse of bladder cancer the treatment included 6 courses of chemotherapy by carboplatin, methotrexate, vinblastin. The dose of carboplatin was calculated by AUC-6 index.

Patients in both groups were observed throughout the year and depending on the long-term results. Two above-mentioned groups were divided into two subgroups: those with the achieved objective response (stabilization or partial response) or with progression of the disease. The results of treatment were evaluated by computer tomography using the RESIST criteria; the computer tomography was carried out before treatment and every 8 weeks during therapy.

\subsection{Induced Biochemiluminescence}

Free radical activity (FRA) was estimated by the method of induced biochemiluminescence [9] on BKhL-07 biochemiluminometer conjugated with IBM computer. BKhL-07 is designed to register light fluxes that occur in biological samples as a result of the flow of enzymatic and chemical processes. The method is based on the fact that in the present system the catalytic decomposition of hydrogen peroxide by metal ions with variable valence-ferrous iron occurs: $\mathrm{ROOH}+\mathrm{Fe}^{2+} \rightarrow \mathrm{RO}^{\bullet}+\mathrm{OH}^{-}+\mathrm{Fe}^{3+}$ (Fenton reaction). The resulting $\mathrm{RO}^{\bullet}$ and $\mathrm{OH}^{-}$react with activation of free radical oxidation in a biological substrate which leads to the formation of an unstable tetroxide which disintegrates with the release of a quantum of light recorded at BHL-07. The intensity of the luminescence process is affected by the full complex of compounds with both oxidative and prooxidant effects.

$0.1 \mathrm{ml}$ of blood plasma, $0.4 \mathrm{ml}$ of phosphate buffer $(\mathrm{pH}=7.5), 0.4 \mathrm{ml}$ of ferrous sulfate solution $(0.05 \mathrm{mMol})$ were added to the measuring cuvette. The cuvette was placed in BHL-07, and then $0.2 \mathrm{ml}$ of $2 \%$ hydrogen peroxide solution was added. Measurement of free radical activity occurs automatically.

An informative indicator $\left(\mathrm{I}_{\max }\right)$ is the maximum intensity of the glow of the sample under investigation measured in pulses/sec. $\mathrm{I}_{\max }$ reflects the free radical activity of the sample.

\subsection{Oxidative Modification of Proteins}

The oxidative modification of proteins (OMP) was determined by the level of carbonyl derivatives found in reaction with 2,4-dinitrophenylhydrazine [10]. 
The method is based on the reaction of interaction between the oxidized amino acid protein residues with 2,4-dinitrophenylhydrazine (2,4-DNPH) with formation of 2,4-dinitrophenylhydrazones which are spectrophotometrically detected.

Control and experimental samples contained $0.05 \mathrm{ml}$ of serum and $0.95 \mathrm{ml}$ of phosphate buffer ( $\mathrm{pH} 7.4$ ), $1 \mathrm{ml}$ of solution of 2,4-DNPH was poured into the experimental samples, and $1 \mathrm{ml}$ of $2 \mathrm{~N} \mathrm{HCl}$ was added to the control samples. To precipitate proteins, $1 \mathrm{ml}$ of $1 \mathrm{~N}^{-\mathrm{HClO}_{4}}$ was added to each sample. Samples were incubated at room temperature for one hour, and then centrifuged at $3000 \mathrm{rpm}$ for $15 \mathrm{~min}$. The precipitate was washed by adding $3 \mathrm{ml}$ of a mixture of ethyl acetate-ethanol (1:1), centrifuged at $3000 \mathrm{rpm}$ for $15 \mathrm{~min}$. When this occurred, the extraction of lipids and 2,4-DNPH, which did not react with the carbonyl groups of oxidized proteins, took place. The obtained precipitate was dissolved in $8 \mathrm{M}$ urea solution. The carbonyl derivatives obtained as a result of the oxidative modification of the proteins interacted with 2,4-DNPH to form 2.4 dinitrophenyl hydrazones.

The family of DNPH-derivatives includes aldehyde (ADNPH) and ketone derivatives.

$230 \mathrm{~nm}$-aliphatic aldehyde dinitrophenylhydrazones of neutral nature (ADNPH)

$270 \mathrm{~nm}$ - aliphatic aldehyde dinitrophenylhydrazones of basic nature

$370 \mathrm{~nm}$ - aliphatic ketone dinitrophenylhydrazones of basic nature

$430 \mathrm{~nm}$ - aliphatic aldehyde dinitrophenylhydrazones of basic nature

$530 \mathrm{~nm}$ - aliphatic ketone dinitrophenylhydrazones of basic nature [7] [11].

\subsection{Statistical Analysis}

The obtained results were statistically processes using the Statplus software package, "AnalystSoft», 2018. While estimating the data set of biochemical parameters of patients with malignant tumors of epithelial tissues according to Shapiro-Wilk test, the normality of distribution was not confirmed; that is why for estimation of the significance in differences with the data of the control group the methods of nonparametric statistics were used: Mann Whitney U-test and Kolmogorov-Smirnov test. To analyze the correlation of the data of two samples, the Spearman correlation coefficient was used. Differences were considered to be statistically significant at $\mathrm{p}<0.05$.

\subsection{Ethics}

Data from PS were aggregated and de-linked from personal information related to patients, medical institutions, and pharmacies: these are anonymous data. Therefore, no ethical issues are posed by the use of these data for this study.

\section{Results}

\subsection{Free Radical Activity of Blood Plasma}

Free radical activity of blood plasma increased at all stages of carcinogenesis as 
compared with healthy people (Figure 1).

At the $\mathrm{III}^{\text {rd }}$ and $\mathrm{IV}^{\text {th }}$ stages a higher statistically significant increase in free radical activity was observed which greatly exceeds that at the $\mathrm{I}^{\text {st }}, \mathrm{II}^{\text {nd }}$ stages. The high level of $I_{\max }$ is likely due to the presence of distant metastases and this fact is reflected in the availability of reliable interconnection between these two parameters $(r=0.456)$. Thus, an increase is shown in free radical activity of blood plasma from the first stage of malignancies of epithelial tissues with further increase in subsequent stages which can be due to the detected activation of free radical oxidation at metastasis.

\subsection{Oxidative Protein Modification}

A significant activation of the total OMP was observed in malignant tumors of epithelial tissues, as evidenced by an increase in the content of carbonyl derivatives of proteins in the plasma, starting from the $\mathrm{I}^{\text {st }}$ stage of disease (by $71 \%$, $146 \%, 259 \%$ and $82 \%$, respectively) (Figure 2).

Special attention was paid to the activity of OMP at the initial and terminal stages of the disease, which demonstrate no great differences. But the analysis of the distribution of carbonyl derivatives of different wavelength showed a significant decrease of the OMP activity as compared to actually healthy people for the $\mathrm{I}^{\text {st }}$ stage of cancer (Figure 3 ).

A statistically significant reduction in absorption level is observed registered at $230 \mathrm{~nm}$ wavelength where aliphatic ADNPH of neutral nature are found. These compounds are the markers of protein fragmentation. On the contrary, the content of carbonyl derivatives at wavelengths of 270, 370 and 430 statistically significantly increases (Figure 3).

In the terminal (IV) stage of malignant neoplasms the level of phenylhydrazones, determined at 230,370 and $530 \mathrm{~nm}$, is significantly increased, that is, aliphatic ketone dinitrophenyl hydrazones are predominant which are the markers of protein aggregation characteristic of the later stages of oxidative stress (Figure $4)$.

With the development of the objective effect in patients after the $1^{\text {st }}$ course of treatment a statistically significant reduction of free radical activity of blood plasma is observed, in average by $20 \%$ (Figure 5). In the subsequent progression of tumor a tendency is shown to increase in free radical activity of blood plasma after the $1^{\text {st }}$ course of treatment.

With objective effect of polychemotherapy, the significant differences in the level of blood plasma OMP proteins with that before treatment were not found (Figure 6).

An increase in free radical activity of blood plasma in the absence of objective effect after polychemotherapy was accompanied by the activation of the total OMP - by 2.83 times in patients with recurrent colon cancer and by 2 times in patients with recurrent bladder cancer (Figure 6).

Analysis of phenylhydrazones distribution at different wavelengths, depend- 
ing on the efficiency of cytostatic therapy, did not show significant changes in the case of disease progression (Figure 7, Figure 8).

Common to the cases of the objective effects of polychemotherapy has been a dramatic increase in the carbonyl derivatives recorded at $230 \mathrm{~nm}$ (Figure 9, Figure 10).

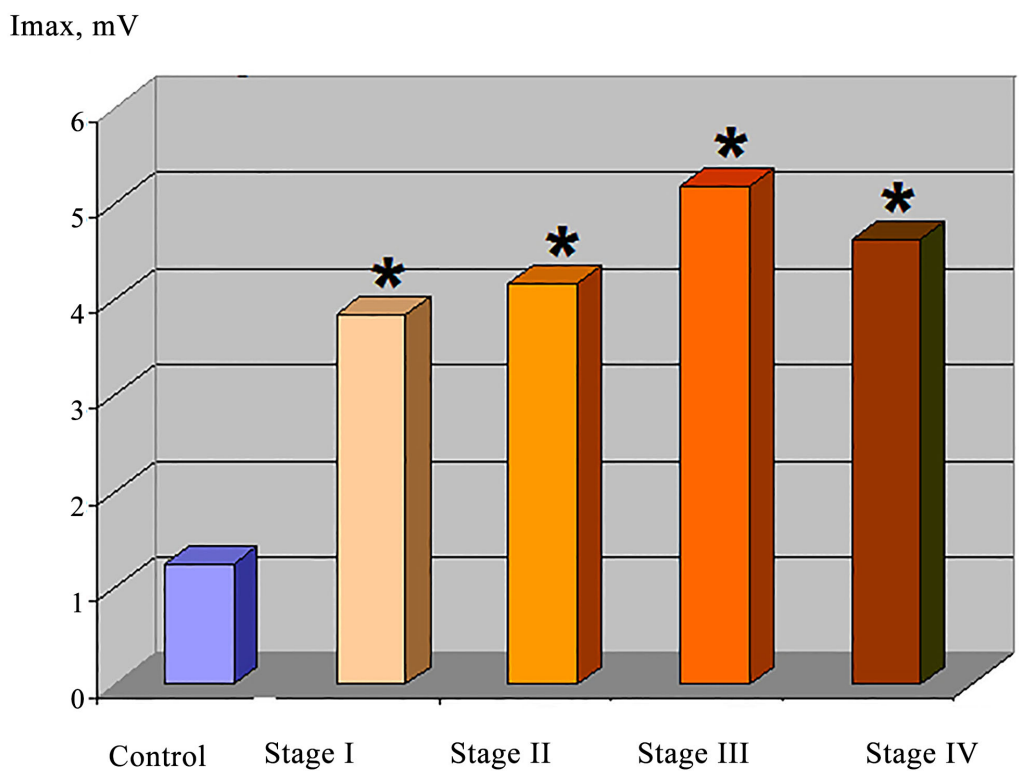

Figure 1. Free radical activity of the blood plasma of patients with malignant tumors of epithelial tissues. $\square$-the group of actually healthy people the patients with different stages of carcinogenesis not previously subjected to anti-tumor treatment: $\square-\mathrm{I}^{\text {st }}$ stage, $\square-\mathrm{II}^{\text {nd }}$ stage, $-\mathrm{III}^{\text {rd }}$ stage, $\square-\mathrm{IV}^{\text {th }}$ stage. Note: ${ }^{*}$-the differences with indices of the control group are significant $(\mathrm{p}<0.05)$.

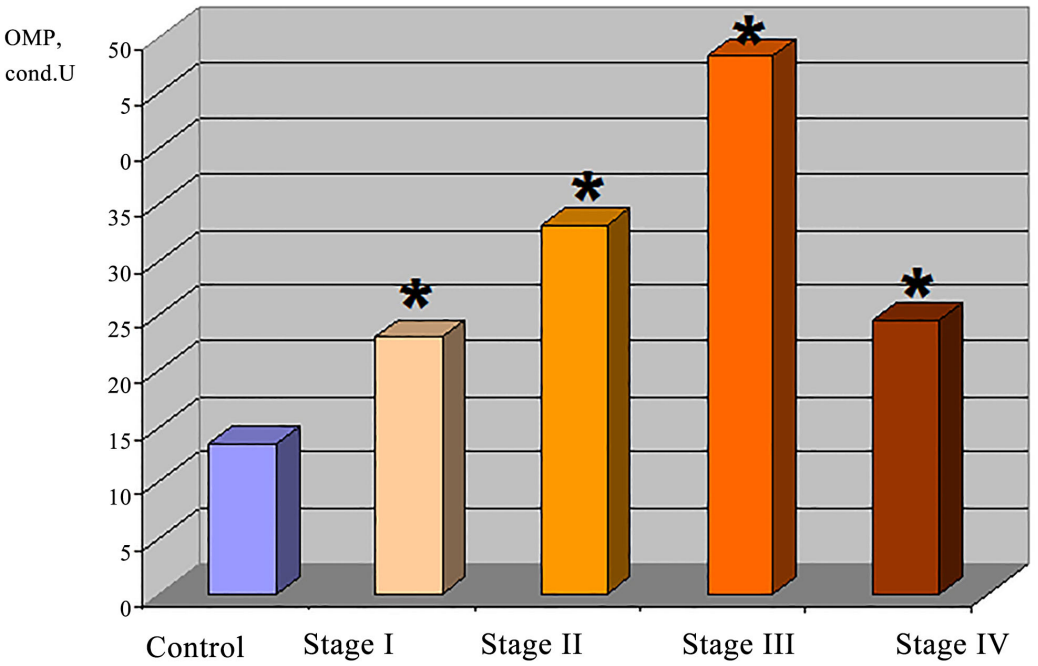

Figure 2. Oxidative modification of blood plasma proteins of patients with malignant tumors of epithelial tissues. $\square$-the group of actually healthy people, the patients with different stages of carcinogenesis not previously subjected to anti-tumor treatment: $\square-\mathrm{I}^{\text {st }}$ stage, $\square-\mathrm{II}^{\text {nd }}$ stage, $\_-\mathrm{III}^{\text {rd }}$ stage, $\square-\mathrm{IV}^{\text {th }}$ stage. Note: ${ }^{*}$ - the differences with indicators of actually healthy people are significant $(\mathrm{p}<0.05)$. 


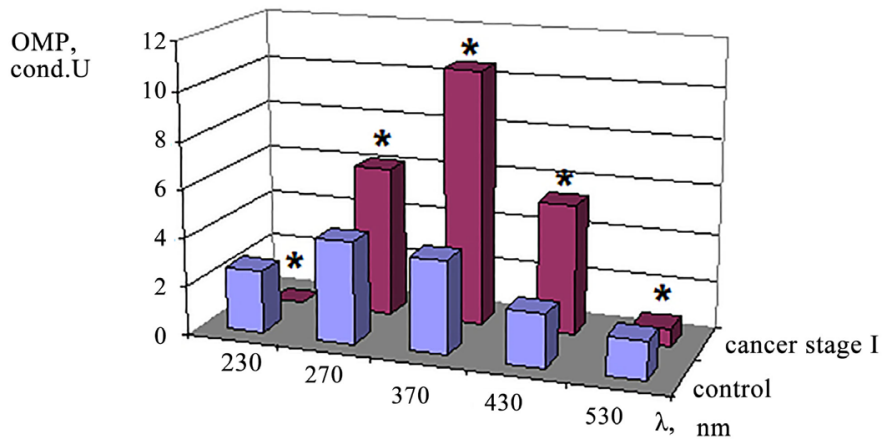

Figure 3. Spontaneous OMP blood plasma in patients with malignant tumors of epithelial tissues ( $\mathrm{I}^{\text {st }}$ stage) as compared to actually healthy people. Note: ${ }^{*}$-the differences with indicators of actually healthy people are significant $(\mathrm{p}<0.05)$.

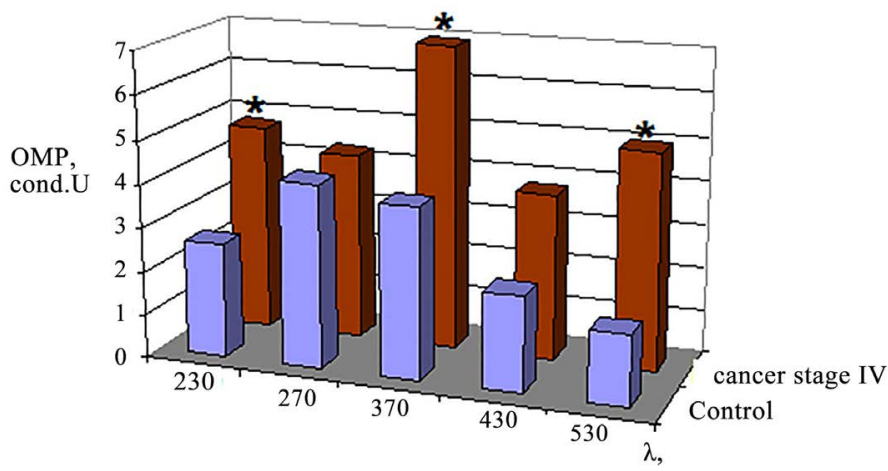

Figure 4. Spontaneous OMP blood plasma in patients with malignant tumors of epithelial tissues (IV ${ }^{\text {th }}$ stage) compared with actually healthy people. Note: ${ }^{*}$-the difference with indicators of actually healthy people is significant $(\mathrm{p}<0.05)$.

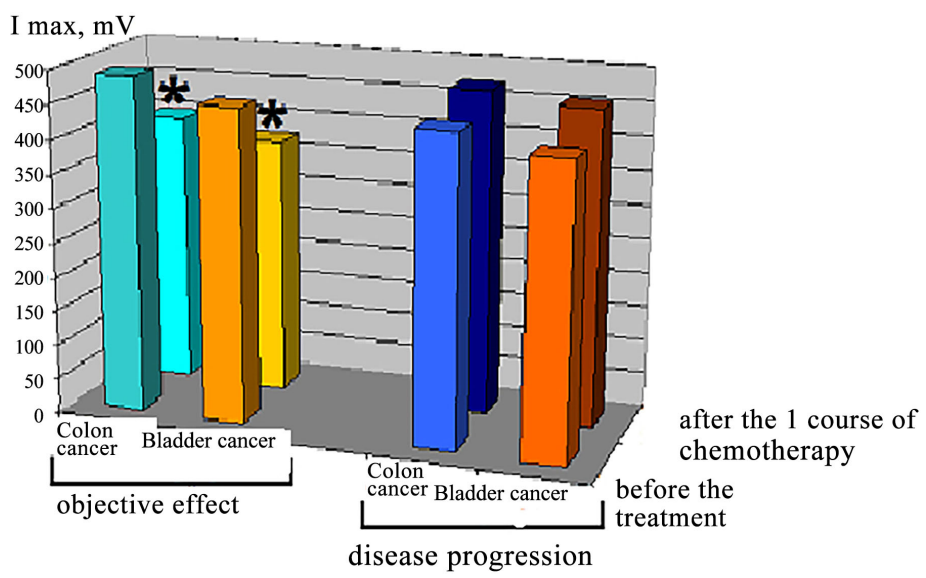

Figure 5. Free radical activity of blood plasma in patients before treatment and after the $1^{\text {st }}$ course of chemotherapy. $\square \square$-patients with colon cancer before anti-tumor treatment and after the $1^{\text {st }}$ course of polychemotherapy; $\square \square$-patients with bladder cancer before anti-tumor treatment and after the $1^{\text {st }}$ course of polychemotherapy; $\square \square$-patients with colon cancer before anti-tumor treatment and with progression of the disease after the $1^{\text {st }}$ course of polychemotherapy; $\square \square$-patients with bladder cancer before treatment and with progression of the disease after the $1^{\text {st }}$ course of polychemotherapy. Note: * - the differences with the values before chemotherapy are statistically significant $(\mathrm{p}<$ $0.05)$. 


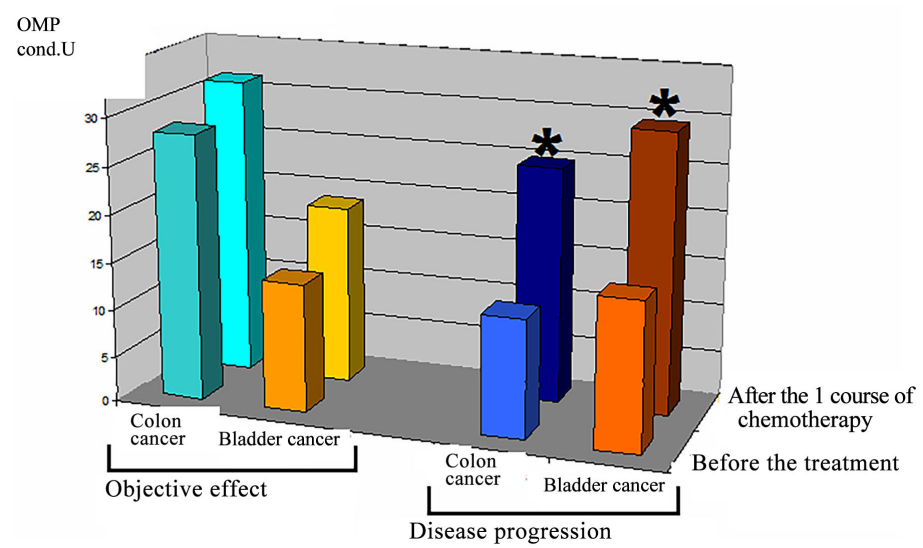

Figure 6. Oxidative modification of plasma proteins in patients before treatment and after the $1^{\text {st }}$ course of polychemotherapy. $\square \square$-patients with colon cancer before anti-tumor treatment and with objective effect after the $1^{\text {st }}$ course of polychemotherapy; $\square \square$-patients with bladder cancer before anti-tumor treatment and with objective effect after the $1^{\text {st }}$ course of polychemotherapy; $\square \square$-patients with colon cancer before anti-tumor treatment and with progression of the disease after the $1^{\text {st }}$ course of polychemotherapy; $\square \square$-patients with bladder cancer before anti-tumor treatment and with progression of the disease after the $1^{\text {st }}$ course of polychemotherapy. Note: ${ }^{*}$-the differences with values before chemotherapy are statistically significant $(\mathrm{p}<0.05)$.

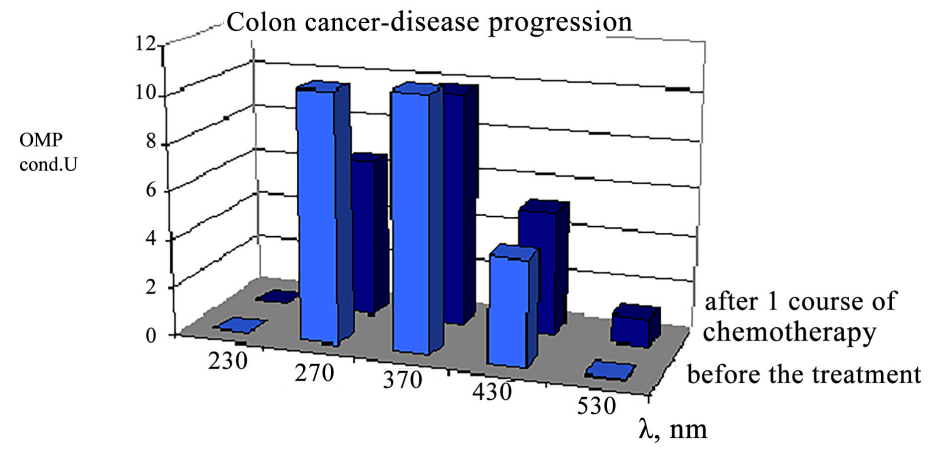

Figure 7. Spontaneous OMP of blood plasma in patients with bowel cancer before treatment and after the $1^{\text {st }}$ course of polychemotherapy in the absence of an objective treatment effect.

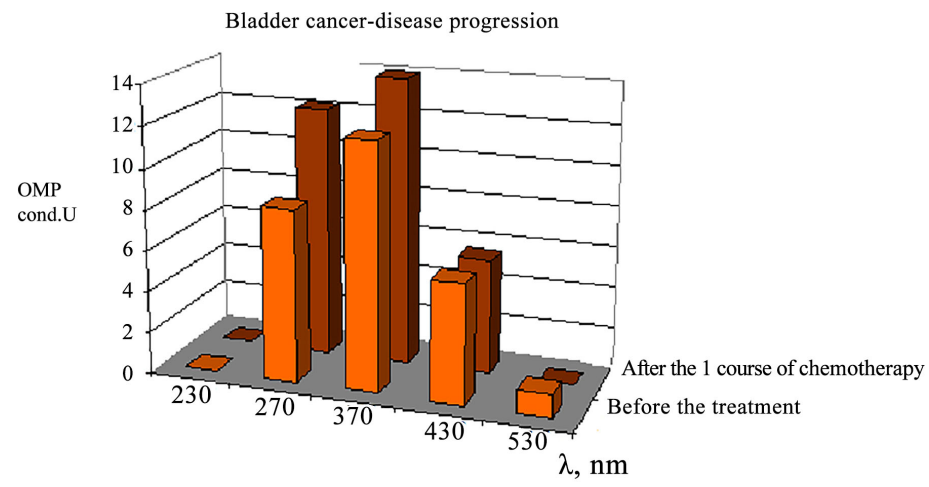

Figure 8. Spontaneous OMP of blood plasma in patients with bladder cancer before treatment and after the $1^{\text {st }}$ course of polychemotherapy in the absence of an objective treatment effect. 


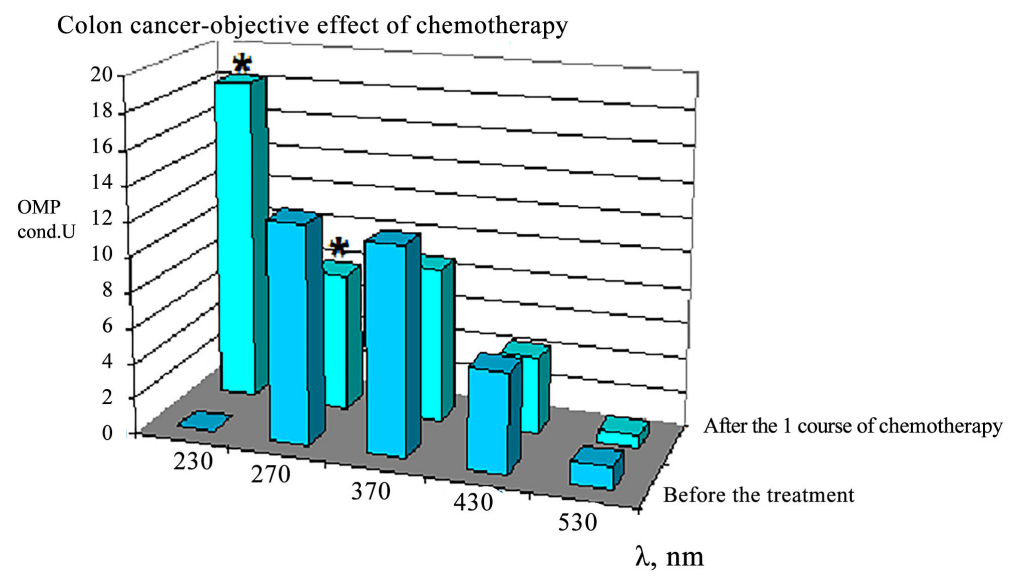

Figure 9. Spontaneous OMP of blood plasma in patients with bowel cancer before treatment and after the $1^{\text {st }}$ course of polychemotherapy in presence of the objective effect of treatment. Note: ${ }^{\star}$ - the differences with values before chemotherapy are statistically significant $(\mathrm{p}<0.05)$.

Bladder cancer-objective effect of chemotherapy

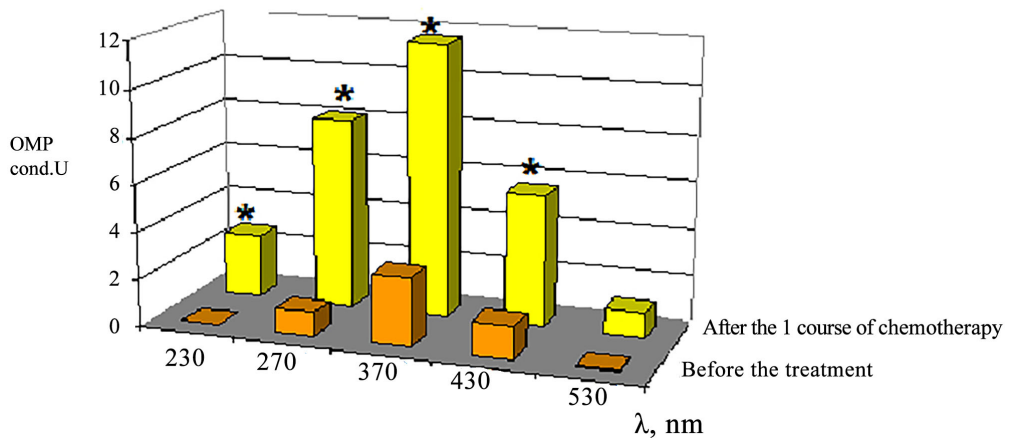

Figure 10. Spontaneous OMP of blood plasma in patients with bladder cancer before treatment and after the $1^{\text {st }}$ course of polychemotherapy in the presence of the objective effect of treatment. Note: ${ }^{*}$-the differences with values before chemotherapy are statistically significant $(\mathrm{p}<0.05)$.

\section{Discussion}

Cancer is the fatal disease that is mostly determined at the later stages and accompanied with the appearance of metastasis. Moreover there are no objective markers to determine the efficacy of chemotherapy treatment. That is why the aim of investigation was to establish relationship between free radical activity in blood and tumor progression, from one side, and the correlation between investigating parameters and efficiency of chemotherapy, from another side. It is well known that the participation of ROS, in particular, of superoxide radical and hydrogen peroxide, involves in the regulation of cell proliferation [12]. Besides, in the processes of metastasis a significant role belongs to matrix metalloproteinases-the extra-cellular family of zinc-dependent endopeptidases capable of destroying all kinds of extra-cellular matrix proteins [13]. Regulation of the activity of these enzymes is also carried out by ROS [14]. 
The proteins are one of the main substrates, affected by ROS. Carbonyl fragments of polypeptide chain, defined as 2,4-dinitrophenylhydrazones [15], serve as the final oxidation products. The modified protein molecules are easier subjected to proteolysis with formation of peptides of average molecular weight which are one of the components of endogenous intoxication [16]. OMP generates new antigens and provokes an immune response [17] [18]. Products of such modification may cause secondary damage to other biomolecules [19]. The appearance of substantial amounts of modified proteins provokes the development of immune responses (macrophage activation and oxygen blast) not only to modified proteins but also to normal molecules. Inactivation of proteins occurs simultaneously with their modification [20] [21].

In the early stages of oxidative stress the aldehyde phenylhydrazones are dominated $(230 \mathrm{~nm}$-aldehydes of neutral nature, $270 \mathrm{~nm}$-aldehydes of the basic nature), and in the later stages-the ketone dinitrophenyl hydrazones of basic nature $(370 \mathrm{~nm})$ [22]. Under the effect of ROS the fragmentation of proteins can occur [23].

The increase in the total level of OMP, accompanying the previously shown increase of free radical activity of blood plasma, at various stages of cancer is due to different fractions of carbonyl derivatives. In the initial stages of the disease this increase is due to aldehyde and ketone $\mathrm{DNPH}$, indicating the realization of both the processes of fragmentation of proteins and their aggregation. In the terminal stage the increase in OMP is due to aliphatic ketone dinitrophenyl hydrazones which are the markers of protein aggregation characteristic of the later stages of oxidative stress.

With the development of the objective effect in patients after the $1^{\text {st }}$ course of treatment a statistically significant reduction of free radical activity of blood plasma is observed. These results might be due to high level of reduced glutathione, low-molecular compound of nonprotein nature which has antiradical activity and to catalase activity in tumor cells, which is probably a factor of resistance of tumors to free radical stress and to entrance of these compounds into systemic circulation [24]. In the subsequent progression of tumor a tendency is shown to increase in free radical activity of blood plasma after the $1^{\text {st }}$ course of chemotherapy treatment.

At $230 \mathrm{~nm}$ wavelength ADPH of neutral nature are determined characterizing the appearance of oxidized modified oligopeptides resulting from the destruction of cellular proteins. It can be assumed that these substances are formed as a result of destruction of malignant tumor cells in the presence of an objective effect of treatment.

\section{Conclusion}

A statistically significant increase in free radical activity and in degree of oxidative modification of blood plasma proteins is shown starting from the first stage of malignancy of epithelial tissues. In the initial stages of carcinogenesis the level 
of oxidative modification of blood plasma proteins increases both due to the aldehyde and ketone carbonyl derivatives which indicates the realization of both processes of protein fragmentation and of their aggregation. At the terminal stage of malignancies the increase in oxidative modification of proteins is due to aliphatic ketone dinitrophenyl hydrazones being the markers of protein aggregation characteristic of the late stages of oxidative stress. In the case of objective response to polychemotherapy, a statistically significant reduction of free radical activity of blood plasma was found after the first course of chemotherapy by cytostatics as well as a statistically significant increase in carbonyl derivatives registered at $230 \mathrm{~nm}$ which can serve as a marker of the efficiency of therapy.

\section{Author Contributions}

In the manuscript preparation, all authors contributed equally until submission.

\section{Conflicts of Interest}

The authors declare no conflicts of interest regarding the publication of this paper.

\section{References}

[1] Semiglazov, V.V. and Topuzov, E.E. (2009) Breast Cancer. MEDpress-Inform, Moscow, 176. [In Russian]

[2] Aschele, C., Lonardi, S. and Monfardini, S. (2002) Thymidylate Synthase Expression as a Predictor of Clinical Response to Fluoropyrimidine-Based Chemotherapy in Advanced Colorectal Cancer. Cancer Treatment Reviews, 28, 27-47. https://doi.org/10.1053/ctrv.2002.0253

[3] Libra, M., Navolanic, P.M., Talamini, R. and Toffoli, G. (2004) Thymidylate Synthetase mRNA Levels Are Increased in Liver Metastases of Colorectal Cancer Patients Resistant to Fluoropyrimidine-Based Chemotherapy. BMC Cancer, 1, 11-17. https://doi.org/10.1186/1471-2407-4-11

[4] Shain, A.A. (2004) Oncology. Izdatel'skii centr Akademiya, Tyumen. [In Russian]

[5] Miki, J., Furusato, B., Li, H., Gu, Y., Takahashi, H., Egawa, S., Sesterhenn, I.A., McLeod, D.G., Srivastava, S. and Rhim, J.S. (2007) Identification of Putative Stem Cell Markers, CD 133, and CXCR_4, in hTERT-Immortalised Primary Nonmalignant and Malignant Tumor_Derived Human Prostate Epithelial Cell Lines and in Prostate Cancer Specimens. Cancer Research, 67, 3153-3161. https://doi.org/10.1158/0008-5472.CAN-06-4429

[6] Naito, Y., Lee, M.-C., Kato, Y., Nagai, R. and Yoshikazu, Y. (2010) Oxidative Stress Markers. Anti-Aging Medicine, 7, 36-44. https://doi.org/10.3793/jaam.7.36

[7] Jones, L.A., Holmes, J.C. and Seligman, R.B. (1956) Spectrophotometric Studies of Some 2,4-Dinitrophenylhydrazones. Analytical Chemistry, 2, 191-198. https://doi.org/10.1021/ac60110a013

[8] Ho, E., Galougahi, K.K., Liu, C.-C., Bhindi, R. and Figtree, G.A. (2013) Biological Markers of Oxidative Stress: Applications to Cardiovascular Research and Practice. Redox Biology, 1, 483-491. https://doi.org/10.1016/j.redox.2013.07.006

[9] Kuz'mina, E.I., Nelyubin, A.S. and Shchennikova, M.K. (1983) Application of Induced Chemoluminescence for Assessment of Free Radical Reactions in Biological 
Substrates. Mezhvuzovskii sbornik biokhimii i biofiziki mikroorganizmov. Gorky, 179-183. (In Russian)

[10] Dubinina, E.E., Burmistrov, S.O., Khodov, D.A. and Porotov, I.G. (1995) Oxidative Modification of Human Blood Plasma Proteins, the Method of Its Determination. Voprosy meditsinskoi khimii, 1, 24-26. (In Russian)

[11] Dubinina, E.E. (2006) Products of Oxygen Metabolism in Functional Activity of Cells (Life and Death, Creation and Destruction). Fiziologicheskie i kliniko-boikhimicheskie aspekty. SPb.: Meditsinskaya pressa, 440. (In Russian)

[12] Sarsour, E.H., Kumar, M.G., Chaudhuri, L. and Goswami, P.C. (2009) Redox Control of the Cell Cycle in Health and Disease. Antioxidants \& Redox Signaling, 12, 2985-3011. https://doi.org/10.1089/ars.2009.2513

[13] Chakraborti, S., Mandal, M., Das, S., Mandal, A. and Chakraborti, T. (2003) Regulation of Matrix Metalloproteinases: An Overview. Molecular and Cellular Biochemistry, 1-2, 269-285. https://doi.org/10.1023/A:1026028303196

[14] Browatzki, M., Larsen, D., Pfeiffer, C.A., Gehrke, S.G., Schmidt, J., Kranzhofer, A., Katus, H.A. and Kranzhofer, R. (2005) Angiotensin II Stimulates Matrix Metalloproteinase Secretion in Human Vascular Smooth Muscle Cells via Nuclear Factor-KappaB and Activator Protein 1 in a Redox-Sensitive Manner. R.J. Vasc. Res, 5, 415-423.

[15] Shugalei, I.V. (2000) Chain Process of Peroxidation of Proteins-A Suitable Model for Investigation of Destructive Ability of Active Forms of Oxygen. Russkii zhurnal VICh/SPID i rodstvennye problem, 1, 77-78. (In Russian)

[16] Pasechnik, I.N. (2004) Oxidative Stress as a Component of Formation of Critical States in Surgical Patients. (In Russian)

[17] Squier, T.C. (2001) Oxidative Stress and Protein Aggregation during Biological Aging. Experimental Gerontology, 9, 1539-1550.

https://doi.org/10.1016/S0531-5565(01)00139-5

[18] Lambeth, J.D. (2007) Nox Enzymes, ROS, and Chronic Disease: An Example of Antagonistic Pleiotropy. Free Radical Biology \& Medicine, 3, 332-347.

[19] Piroddi, M., Depunzio, I., Calabrese, V., Mancuso, C., Aisa, C.M., Binaglia, L., Minelli, A., Butterfield, A.D. and Galli, F. (2007) Oxidatively-Modified and Glycated Proteins as Candidate Pro-Inflammatory Toxins in Uremia and Dialysis Patients. Amino Acids, 4, 573-592. https://doi.org/10.1007/s00726-006-0433-8

[20] Winterbourn, C.C. (2000) Biomarkers of Myeloperoxidase-Derived Hypochlorous Acid Free Radic. Biology and Medicine, 5, 403-409.

[21] Ryabov, G.A., Aziziv, G.A. and Pasechnik, I.N. (2002) Oxidative Stress and Endogenous Intoxication of Patients in Critical States. Vestnik Intensivnoi Terapii, 4, 4-7. (In Russian)

[22] Tolochko, Z.S. and Spiridonov, V.K. (2010) Oxidative Modification of Proteins in Blood of Rats at Destruction of Capsaicin-Sensitive Nerves and Change in the Level of Nitrogen Oxide. Rossiskii fiziologicheskii zhurnal im. I.M. Sechenova, 1, 77-84. (In Russian)

[23] Muravleva, L.E., Molotov-Luchanskii, V.B. and Klyuev, D.A. (2010) Oxidative Modification of Proteins: Problems and Prospects of Investigation. Fundament. Issled, 1, 74-78. (In Russian)

[24] Blokhin, Yu.D. (2004) Phenotype of Multiple Drug Stability of Tumor Cells Due to Destruction of the Program of Cell Death. Vestn. Ramn., 12, 16-20. (In Russian) 